\title{
Sacks O. Hallucinations. New York: Knopf; 2012. p. 288.
}

\author{
"Any consuming passion or threat may lead to hallucinations..."
}

O.S.

\section{Lizardo Cruzado ${ }^{1}$}

Seguramente Oliver Sacks es en la actualidad el más querido y conocido de los neurólogos a nivel mundial y no porque publique eruditos artículos científicos o pergeñe sofisticadas investigaciones basadas en tecnología de punta. Sacks, catedrático de la escuela de medicina de la Universidad de Nueva York, se ha hecho un nombre como narrador de sorprendentes historias de pacientes neuro-psiquiátricos -baste rememorar a The man who mistook his wife for a hat (1) o Awakenings (2)- en las que hace un despliegue de intuición sabia y sensibilidad depurada, y donde a través de su lenguaje llano nos permite abismarnos con deleite en el siempre aún misterioso funcionamiento de la mente y cerebro del ser humano. Una de las gracias de este benéfico periplo es que pareciera que lo efectuamos llevados de la mano de un viejo y sereno maestro a través del laboratorio de un gabinete escolar, tal es la claridad de la perspectiva que Sacks nos ofrece pero sin desmedro de la fina descripción semiológica -su bagaje clínico es muy vasto- y la cumplida explicación de los mecanismos neurobiológicos subyacentes a cada cuadro que nos presenta.

La sociedad en general ha estado, señala Sacks, acostumbrada a pensar axiomáticamente que "escuchar voces" es sinónimo casi indefectible de "locura" y que ello nunca ocurre sino en el contexto de severas alteraciones mentales. A partir de esta constatación, y a modo de refutación frondosa, Sacks compila y expone diversas y peculiares manifestaciones de alucinaciones provenientes de distintos territorios sensoriales y que se asocian a cuadros y situaciones tan disímiles como la epilepsia, el consumo de drogas, el delirium, la narcolepsia, la privación sensorial, la enfermedad de Parkinson, la migraña, los estados de duelo, el síndrome de Charles Bonnet, y varios otros -el mismo autor reseña algunas experiencias personales pues a causa de la migraña y el consumo experimental de sustancias psicoactivas, llegó a tener diversos fenómenos alucinatorios-. Sacks nos recuerda que no fue sino hasta mediados del siglo XIX que se estableció el significado actual del término alucinación pues antes designaba simplemente a una mentalidad fantasiosa o divagante mientras que el fenómeno en sí solía nombrarse con los términos venerables de "aparición" o "visión" e inclusive constituía parte de la entonces normalidad pedestre y cotidiana.

Tal vez sorprenda constatar que pese a la tantas veces repetida definición esquiroleana sobre la alucinación como una percepción sin objeto, no exista hoy una definición realmente acabalada y de consenso que distinga taxativamente la alucinación de otros fenómenos psicosensoriales. Probablemente esto es reflejo de que el rubro de las alucinaciones ha sido frecuentemente descuidado en la psiquiatría por la dificultad de su disección psicopatológica -evóquese si aparte del monumental Traité des Hallucinations de $\mathrm{H}$. Ey existe alguna otra obra de tal envergadura sobre el tema, sino hasta el recientísimo Hallucinations - Research and practice (3)-. Es ciertamente arduo el intento de comprender psicológicamente una alucinación si uno no la ha padecido. Esto, se ha demostrado, influye en el distanciamiento que el médico en ciernes y el médico no psiquiatra adoptan hacia los pacientes psiquiátricos y podría paliarse con ingeniosos recursos educativos que permitan simular la vivencia alucinatoria y así romper tal lamentable barrera (4). Sin duda, la lectura de libros sugerentes y seductores como Hallucinations, también sería de fructuoso beneficio para este propósito.

Psiquiatra. Universidad Peruana Cayetano Heredia. Instituto Nacional de Salud Mental Honorio Delgado Hideyo Noguchi. Lima, Perú. 
Otro aspecto que ha entorpecido la mejor comprensión de los fenómenos alucinatorios por el público lego y hasta el especializado ha sido la errónea identificación de la percepción como un mecanismo de captura objetiva y fidedigna de la realidad (a la manera de una cámara fotográfica que capta automáticamente una imagen) cuando en realidad la percepción es un proceso intrincadamente complejo. Sin la actitud empática que nos permita representarnos al individuo alucinado como secuestrado en la profunda soledad de sus pseudopercepciones, imposibles de ser validadas o compartidas por el resto, continuaremos estableciendo un muro invisible e indestructible entre ellos y nosotros, y que asociaciones civiles como Intervoice - The International Community for Hearing Voices (5) pretenden derribar.

El libro de Sacks, aunque etiquetable bajo el rubro "de divulgación", sería de notable utilidad inclusive para psiquiatras y otros trabajadores de la salud mental por cuanto es una apretada e ilustrativa síntesis de la literatura sobre el milenario pero aún desconcertante fenómeno de las alucinaciones, a las que ciertamente, bajo ciertas circunstancias, todos podríamos hallarnos susceptibles. Que Sacks ponga en el centro de su preocupación no a las neuronas o sus neurotransmisores sino al ser humano que alucina y lo represente vívidamente en uno de los padecimientos más solitarios y terribles de la experiencia humana, es el principal mérito de este libro.

\section{REFERENCIAS BIBLIOGRÁFICAS}

1. Sacks O. The man who mistook his wife for a hat. New York: Summit Books; 1985.

2. Sacks O. Awakenings. New York: Gerald Duckworth \& Company; 1973.

3. Blom JD, Sommer IEC. Hallucinations - Research and practice. New York: Springer; 2012.

4. Bunn W, Terpstra J. Cultivating empathy for the mentally ill using simulated auditory hallucinations. Acad Psychiatry. 2009; 33: 457-460.

5. http://www.intervoiceonline.org/ 